\title{
Sputtered ZnSnO buffer layers for kesterite solar cells
}

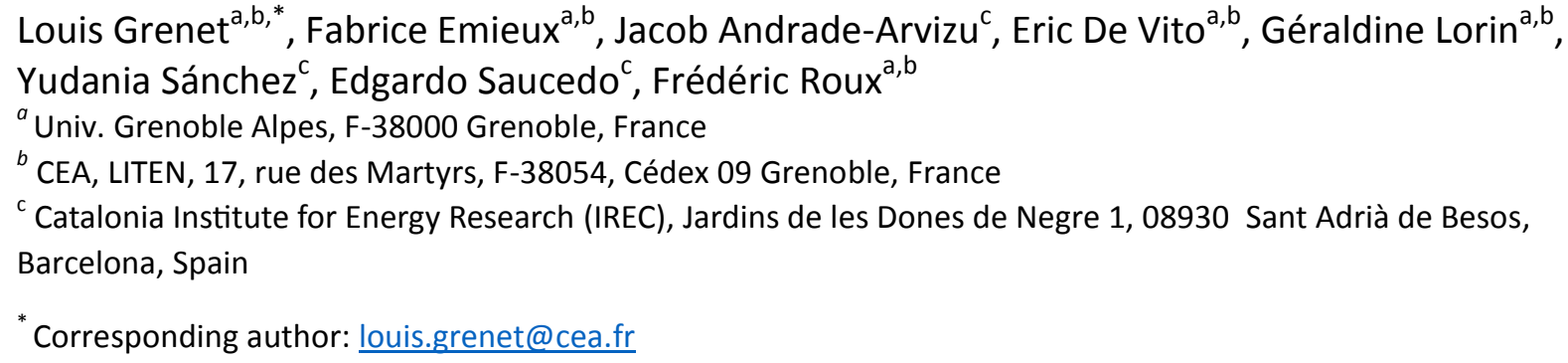

\section{Abstract}

Replacing the CdS buffer layer with a $\mathrm{ZnSnO}$ one in $\mathrm{Cu}_{2} \mathrm{ZnSnS}_{4}$-based solar cells allows both to improve the device performances and to avoid using toxic $\mathrm{Cd}$. Additionally, using a sputtered buffer layer is a major asset for solar cells fabricated by physical vapor deposition processes. In this study, ZnSnO layers are deposited by sputtering of a single metal-oxide target. Structural and optical properties of the layers deposited on $\mathrm{Si}$ or glass are first described. The possibility of modifying the $\mathrm{ZnSnO}$ metallic composition by adjusting the deposition power is demonstrated. Attempts to improve the optoelectronic properties of the $\mathrm{ZnSnO}$ layers with $\mathrm{Ar}: \mathrm{O}_{2}$ or $\mathrm{Ar}_{\mathrm{S}} \mathrm{SF}_{6}$ reactive sputtering are shown as well. These $\mathrm{ZnSnO}$ buffer layers are transferred in Mo/CZTS/ZnSnO/ZnO:Al solar cells. After post-deposition thermal treatment and optimization of the deposition condition (notably with the use of $\mathrm{Ar}: \mathrm{O}_{2}$ or $\mathrm{Ar}: \mathrm{SF}_{6}$ reactive sputtering), a solar cells with a power conversion efficiency of $5.2 \%$ is demonstrated. It is $0.6 \%$ absolute higher than the reference solar cell with a CdS buffer layer. To avoid absorber damaging and achieve high performances, deposition power must be as low as possible. A two stages sputtering process is used to conciliate both the absorber surface preservation and a reasonable deposition time. Last, photovoltaic properties of optimized CZTS- and CZTSe-based solar cells with ZnSnO buffer layers are compared.

Keywords: $\mathrm{Cu}_{2} \mathrm{ZnSnS}_{4}, \mathrm{ZnSnO}$ buffer layer, sputtering, Kesterite solar cells, Cd-free devices, reactive sputtering

\section{Introduction}

In the recent years, $\mathrm{Cu}_{2} \mathrm{ZnSn}(\mathrm{S}, \mathrm{Se})_{4}$ (CZTSSe) materials have attracted a lot of attention due to their potential use in thin film solar cells technologies. The lack of constituting critical raw materials along with their optoelectronic properties makes them candidates to replace highly efficient $\mathrm{Cu}(\mathrm{In}, \mathrm{Ga})(\mathrm{S}, \mathrm{Se})_{2}(\mathrm{CIGS})$ ${ }^{1}$ as absorbers for this application. If the first CZTSSe solar cells were made with pure sulfide compounds (CZTS) ${ }^{2}$, the incorporation of Se allows to increase the power conversion efficiency (PCE) of the devices and reach a record value of $12.6 \%{ }^{3-4}$. However, a very recent renewed interest is observed for pure sulfide solar cells due to their wider bandgap, which would be favorable to decrease the cell-to-module efficiency gap ${ }^{5}$ or even for tandem applications ${ }^{6}$. If the solar cell structure inherited from CIGS technology seems to be suitable for Se-rich CZTSSe absorbers, the unfavorable band alignment at the CZTS/CdS heterojunction ${ }^{7}$ is a clear limit for CZTS-based solar cells. Different groups have successfully replaced the CdS buffer layer by an amorphous ZnSnO (ZTO) layer deposited by Atomic Layer Deposition $(A L D)^{8-10}$. The use of a ZTO buffer layer combines both advantages of avoiding the use of toxic $\mathrm{Cd}$ and improving the device performances due to a better band alignment and transparency. Other Cd-free buffer layers $\left(\ln _{x} S_{y}, Z n M g O, Z n(O, S)\right)$ have been tested as well but none of these solutions can surpass 
the CdS reference ${ }^{7}$ and the use of an hybrid $\ln _{x} S_{y} / C d S$ or $(C d, Z n) S$ layer is necessary to achieve high performances ${ }^{7}$.

As far as deposition process is concerned, the use of sputtering may be advantageous, because it is easily upscalable, incorporable in production line and because no liquid wastes are generated ${ }^{11}$. These advantages are particularly marked when a full physical vacuum deposition (PVD) process is used for the whole solar cell fabrication ${ }^{12}$. In this study, we demonstrate the possibility of depositing amorphous ZTO layers from the sputtering of a single $\mathrm{ZnSnO}$ target. In a first part, material properties of the deposited layers are carefully reviewed as function of the deposition conditions. These ZTO layers are then optimized to maximize the performances of Mo/CZTS/ZTO/ZnO:Al solar cells. Last, the best ZTO layer is transferred in a CZTSe based solar cell. The performances of both CZTS and CZTSe based devices are detailed and compared with those with reference CdS buffer layers.

\section{Experimental methods}

\subsection{Samples preparation}

ZTO layers have been deposited by radio-frequency (RF) sputtering on Si or Soda Lime Glass (SLG) substrates for characterization purposes and on CZTS or CZTSe absorbers to fabricate solar cells. Unless otherwise specified, no surface treatment such as chemical cleaning is applied to absorbers before ZTO deposition. Solar cells are completed with a $350 \mathrm{~nm}$ RF-sputtered ZnO:Al window layer deposited in a MRC2 chamber without intentional sample heating and $\mathrm{Ni}(50 \mathrm{~nm}) / \mathrm{Al}(500 \mathrm{~nm})$ grids thermally evaporated on top of the $0.5 \times 0.5 \mathrm{~cm}^{2}$ devices.

A Plassys chamber is used for ZTO RF-deposition from a single $\mathrm{Zn}_{0.8} \mathrm{Sn}_{0.2} \mathrm{O}(3 \mathrm{~N}$ ) target. The diameter of the target is $101.6 \mathrm{~mm}$ and the target to sample distance is $100 \mathrm{~mm}$. Three mass flow controllers are used to inject the $\mathrm{Ar}$ carrier gas and optionally the $\mathrm{Ar}: \mathrm{O}_{2}(1 \mathrm{at} \%)$ and $\mathrm{Ar}: \mathrm{SF}_{6}(5$ at\%) reactive gases. The pressure in the chamber is the result of the total gas flow. Due to the mass flow controller ranges, the total flow can be regulated between $6.7 \mathrm{sccm}(\sim 0.15 \mathrm{~Pa})$ and $30 \mathrm{sccm}(\sim 1.5 \mathrm{~Pa})$ with a $\mathrm{O}_{2}$ content varying from $0 \%$ to $2 \%$ and a $\mathrm{SF}_{6}$ content from $0 \%$ to $1 \%$ (minimum controllable value : $0.03 \%$ ). Samples can be heated up to $250^{\circ} \mathrm{C}$ during deposition, but unless specified, all depositions have been made without intentional heating. For the parametric studies of the deposition conditions, the parameters (power, pressure, $\mathrm{O}_{2}$ or $\mathrm{SF}_{6}$ content) kept at constant values are clearly indicated on the graphs.

CZTS thin films are grown onto commercial SLG substrates by a sequential process. The SLG substrates are cleaned first in isopropanol and then rinsed in deionized water during 10 minutes in ultrasonic bath. Just after the cleaning process, a $750 \mathrm{~nm}$ molybdenum (Mo) layer is deposited by DC magnetron sputtering (Alliance Concept CT100). The stacked metallic films $(\mathrm{Cu} / \mathrm{Sn} / \mathrm{Cu} / \mathrm{Zn})$ are deposited by DC magnetron sputtering (Alliance Concept 450) where $\mathrm{Cu}, \mathrm{Sn}$ and $\mathrm{Zn}$ elemental targets have been employed. These depositions are optimized to produce Cu-poor and Zn-rich CZT precursor materials. After precursor deposition, the CZT stacked layers are simultaneously sulfurized inside of a graphite box containing sulfur (100 mg) and tin (50 mg) powders, using a tubular furnace and the following two-step annealing process is applied: $15 \mathrm{~min}$ at $250^{\circ} \mathrm{C}\left(100 \mathrm{~Pa}\right.$ Ar pressure) and $30 \mathrm{~min}$ at $570^{\circ} \mathrm{C}\left(10^{5} \mathrm{~Pa} \mathrm{Ar}\right.$ pressure).

CZTSe absorbers are synthesized with a two-step selenization process. $\mathrm{Cu} / \mathrm{Sn} / \mathrm{Cu} / \mathrm{Zn}$ precursors are sputtered in an Alliance Concept equipment onto a Mo coated SLG substrate. Samples are positioned in 
a graphite susceptor with Se pellets and annealed at $520^{\circ} \mathrm{C}$ for 5 minutes at $8.5 \times 10^{4} \mathrm{~Pa}$ Ar pressure in a lamp furnace. Additional details of the CZTSe absorber fabrication are given in Ref. ${ }^{13}$.

\subsection{Characterization}

X-Ray Diffraction (XRD) diffractograms have been acquired in a D8 Advance Bruker AXS with a copper counter electrode X-Ray tube. Scanning Electron Microscopy (SEM) images and Energy Dispersive Spectroscopy (EDS) measurements are performed in a Zeiss LEO 1530 equipment. The composition of the ZTO layer is determined by X-Ray Fluorescence (XRF) in a FISCHERSCOPE ${ }^{\circledR}$ X-RAY XDV-SDD equipment working at $50 \mathrm{kV}$. Elemental profiles in the absorber are measured by Glow Discharge Optical Emission Spectroscopy (GDOES) in a Horiba Profiler II equipment. XPS analyses are performed on a PHI Versaprobe

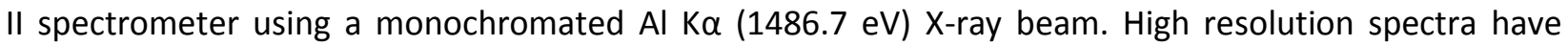
been recorded with a pass energy of $23.5 \mathrm{eV}$ corresponding to an energy resolution of $\sim 0.6 \mathrm{eV}$. Spectra have been fitted by using Multipak ${ }^{\circledR}$ software.

A Spectra-Nova's CT Series Solar Cell Tester is used to perform current-voltage (J-V) measurements under simulated AM1.5G spectrum $\left(100 \mathrm{~mW} . \mathrm{cm}^{-2}\right)$. All J-V measurements (light and dark) are performed at $25^{\circ} \mathrm{C}$ in a four-point probe configuration. External quantum efficiency (EQE) measurements are carried out in a ReRa Spequest spectrometer. Transmission measurements have been carried out in a Perkin Elmer UV/Vis/NIR lambda 950 spectrophotometer with a $150 \mathrm{~mm}$ integration sphere.

\section{Results and discussion}

\subsection{Material characterization}

\subsubsection{Characterization of the baseline process}

ZTO layers have been deposited both on Si substrates and SLG for characterization purposes. First, the crystallinity of a $400 \mathrm{~nm}$ thick ZTO layer deposited on glass has been determined by XRD (Figure 1 (a)). No clear diffraction pattern is visible neither for layers deposited without intentional heating nor for layers deposited at $200^{\circ} \mathrm{C}$. The shape of the diffraction pattern mostly comes from the SLG substrate (particularly the bump between $20^{\circ}$ and $30^{\circ}$ ) and the contribution of the ZTO layer is visible with a very broad shoulder around $35^{\circ}$. According to ${ }^{14}$, this signal suggests the unique presence of an amorphous phase or an amorphous phase with a very small contribution of $\mathrm{SnO}_{2}$ particles (arising from the (101) $\mathrm{SnO}_{2}$ peak). Heating the ZTO layer at elevated temperature $\left(>200^{\circ} \mathrm{C}\right)$ may have a significant impact on carrier transport and device electrical properties for different reasons. Among other things, one can find layer crystallization, shallow dopant activation or interface modification. As no crystallization is observed with deposition temperature, all layers are deposited without intentional heating in the following and other effects (such as possible dopant activation) are checked with post-deposition annealing treatments (hot-plate annealing of the layer or of the full device in air once the deposition is completed).

A SEM cross-section picture of a ZTO layer deposited on $\mathrm{Si}$ is shown in Figure 1 (b). It appears as perfectly smooth, homogeneous and flat, without grain boundaries and with a very limited roughness. The morphology of the layer is very comparable to those obtained with ALD deposition ${ }^{15}$. A $\sim 50 \mathrm{~nm}$ thick ZTO layer in a CZTS/ZTO/ZnO:Al structure is depicted in Figure 1 (c) as well. At this scale, the deposition seems to be very conformal and the morphology of the layer remains unchanged compared to thicker layer on $\mathrm{Si}$. 


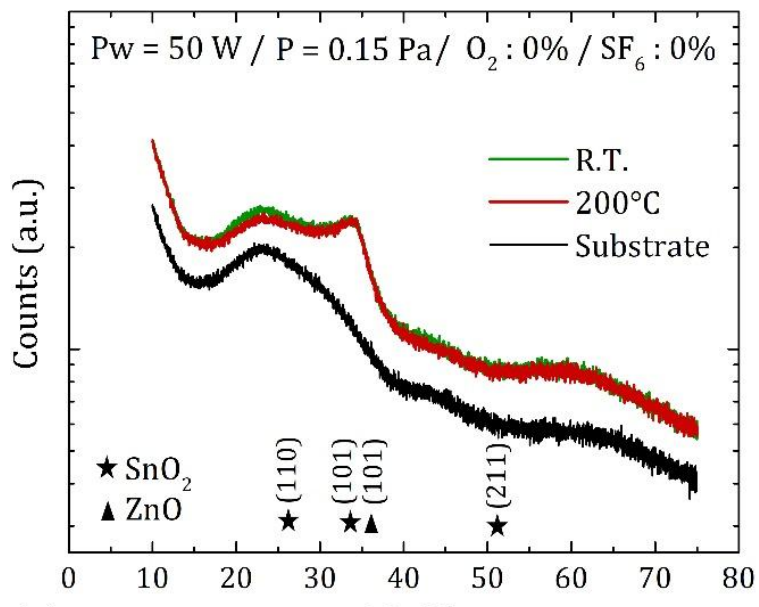

(a)

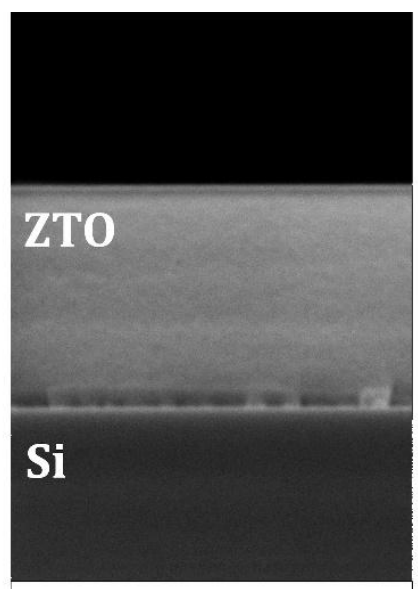

(b)

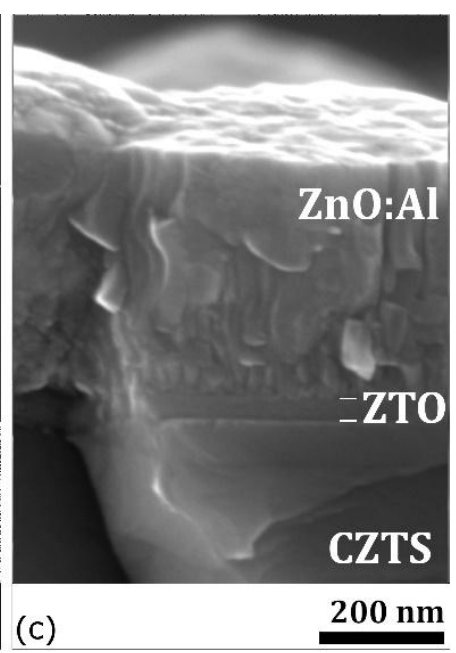

Figure 1: (a) XRD diffractogram of a ZTO layer deposited on SLG without intentionnal heating (R.T.) and at 200 ${ }^{\circ} \mathrm{C}$. The pattern of the SLG substrate in black is vertically translated for clarity. The position of the main tetragonal $\mathrm{SnO}_{2}$ peaks (PDF 00-021-1250) and hexagonal ZnO (PDF 00-036-1451) are indicated with stars and triangle respectively. (b) SEM cross section of a ZTO layer deposited on Si. (c) SEM cross-section of a CZTS/ZTO/ZnO:Al structure.

\subsubsection{Effect of the deposition power}

First, the deposition power has been varied from $10 \mathrm{~W}\left(0.12 \mathrm{~W} . \mathrm{cm}^{-2}\right)$ to $200 \mathrm{~W}\left(2.47 \mathrm{~W} . \mathrm{cm}^{-2}\right)$ resulting in a modification of the layer composition as shown in Figure 2 (a). The [Sn]/([Sn] $+[\mathrm{Zn}])$ ratio measured by XRF varies from $18.5 \%$ to $24.9 \%$ with the power increase, which is in the range of the optimum composition for the state-of-the-art CZTS/ZTO devices ${ }^{16}$. It can be noticed as well that a large range of compositions (from $20 \%$ to $33 \%$ ) allows to reach high efficiencies ${ }^{9}$. The $[0] /([\mathrm{Sn}]+[\mathrm{Zn}]$ ) ratio (measured by EDX) is not sensitive to the deposition power and values between $55 \%$ and $58 \%$ have been measured in all samples. The impact of the deposition power on optical properties is shown in Figure 2 (b). The long wavelength transmission is not affected by the deposition power (variations in the interference fringes are due to the slightly different layer thicknesses). On the contrary, the optical bandgap (roughly determined by the maximum of the transmission $1^{\text {st }}$ derivative) shifts to lower energies with increasing the deposition power, which is attributed to an increase in Sn content ${ }^{17}$. 

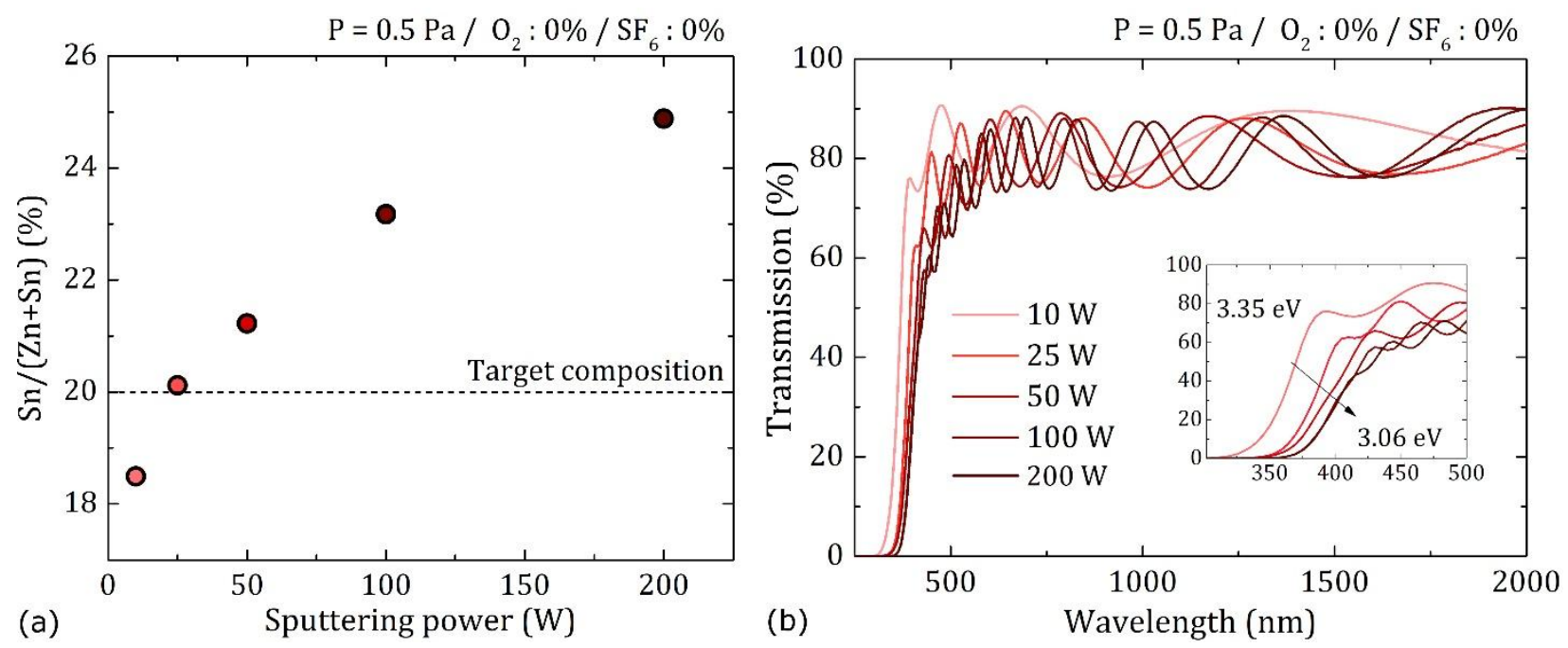

Figure 2: (a) Composition of the ZTO layer measured by XRF as a function of the sputtering power. (b) Transmission curves of the ZTO layer deposited on SLG as a function of the deposition power.

The deposition pressure, only governed by the Ar flow in the chamber, has almost no effect on the optical properties of the ZTO layer (Figure 3). A small shift in the absorption edge towards small energies is visible with increasing pressure. The bandgap shift is negligible, which is consistent with the absence of composition modification (both $[\mathrm{Sn}] /([\mathrm{Sn}]+[\mathrm{Zn}])$ and $[\mathrm{O}] /([\mathrm{Sn}]+[\mathrm{Zn}])$ are constant with the deposition pressure). At high pressure, the transmission decrease at wavelengths smaller to the bandgap is attributed to the stronger absorption due to thicker ZTO layer as revealed by the more tightened interference fringes. The impact of the deposition pressure on the optical properties is marginal and high pressure conditions are used in the following since it allows a finer control of the reactive sputtering process.

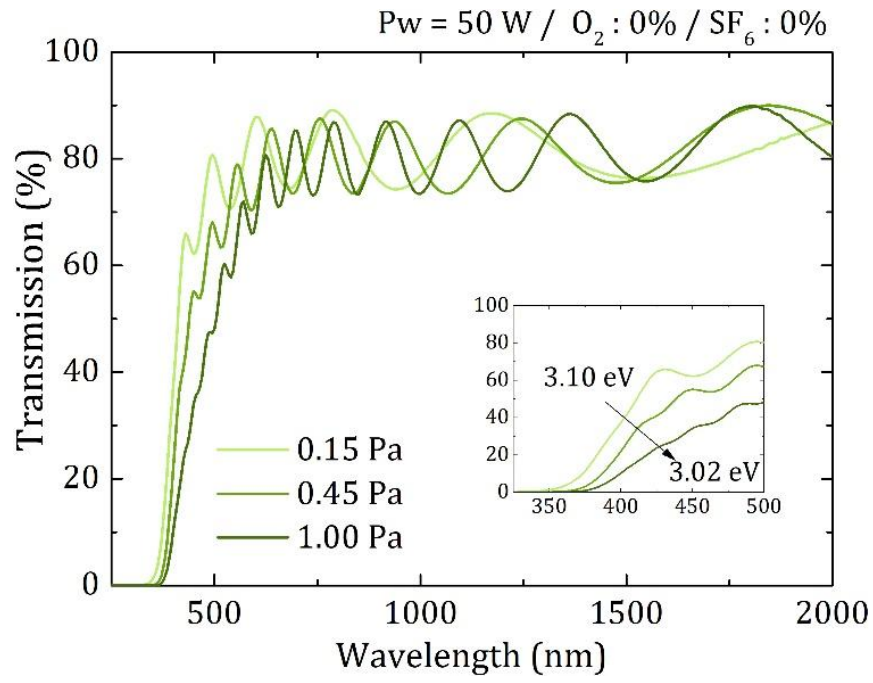

Figure 3: Transmission curves of the ZTO layer deposited on SLG as a function of the deposition pressure. 


\subsubsection{Reactive sputtering with $\mathrm{O}_{2}$ or $\mathrm{SF}_{6}$}

As potential parameters to further improve the performances of CZTS/ZTO/ZnO:Al devices, reactive sputtering with oxygen or sulfur hexafluoride can be tested. It consists in adding small amount of gases $\left(\mathrm{O}_{2}\right.$ or $\mathrm{SF}_{6}$ respectively) in the Ar carrier gas in order to react with the target material to modify the chemical deposition of the deposited layer.

In the first case, oxide layers are generally more transparent and less conductive when RF-sputtered in $\mathrm{Ar}: \mathrm{O}_{2}{ }^{18}$. In the second case, $\mathrm{Ar}: \mathrm{SF}_{6}$ reactive sputtering has been tested to increase the conductivity of the ZTO layer. $\mathrm{F}$ is known to be a dopant both for $\mathrm{ZnO}^{19}$ and $\mathrm{SnO}_{2}{ }^{20}$ materials. Accordingly, attempts to fabricate ZTO:F buffer layers are described thereafter.

ZTO sputtering in $\mathrm{Ar}: \mathrm{O}_{2}$ has been performed with an $\mathrm{O}_{2}$ content varying from $0.2 \%$ to $2 \%$. Please note that a decrease in Ar flow (and thus total pressure) is necessary to reach the $2.0 \% \mathrm{O}_{2}$ content. The composition of the ZTO layer (for $\mathrm{Zn}, \mathrm{Sn}$ and $\mathrm{O}$ elements) measured by EDX is insensitive to the $\mathrm{O}_{2}$ content. Transmission curves of the ZTO layers deposited on SLG are shown in Figure 4. At first sight, the curves are very similar and transmission in the long wavelength range is not increased with the $\mathrm{O}_{2}$ content. The inset zoom close to the absorption edge shows higher transmissions at energies higher than the bandgap when using $\mathrm{Ar}: \mathrm{O}_{2}$ instead of Ar. However, this weak gain in transmission for the $190 \mathrm{~nm}$ thick ZTO layer is not expected to have a significant impact on the device $\mathrm{J}_{\text {sc. }}$. The ZTO layer sheet resistance increases with $\mathrm{O}_{2}$ content $\left(\mathrm{R} \square=2.5 \times 10^{4} \Omega \cdot \square^{-1}\right.$ at $0 \% \mathrm{O}_{2}$ and $\mathrm{R} \square=1.2 \times 10^{6} \Omega . \square^{-1}$ at $\left.0.4 \% \mathrm{O}_{2}\right)$, but these values are at the upper limit of our measurement setup.

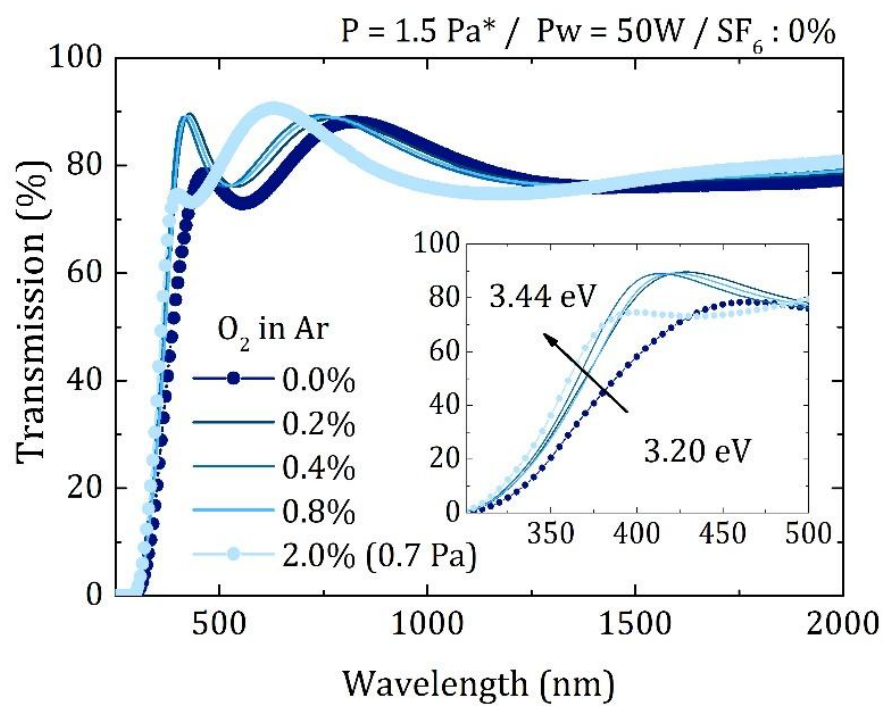

Figure 4: Transmission curves of the ZTO layer deposited on SLG as a function of the $\mathrm{O}_{2}$ content in the carrier gas. Due to the mass flow controller ranges, the total flow has been reduced (and thus the deposition pressure) to reach the highest $\mathrm{O}_{2}$ content (2.0 at\%).

In the case of $\mathrm{F}$ incorporation, $\mathrm{SF}_{6}$ flow from $0.07 \%$ to $1.0 \%$ of the Ar flow ( $30 \mathrm{sccm}$ at $1.5 \mathrm{~Pa}$ ) has been used and the composition of the ZTO:F layers has been measured both by EDX and XPS (Figure 5 (a)). XPS underestimates the $F$ quantity compared to EDX, which can arise either from non-uniform $F$ distribution in the layer ( $F$ depletion at the surface) or from a bad EDX calibration. $F$ profiles have been measured by 
glow discharge spectroscopy but surface artefacts (due to plasma stabilization) prevent conclusions from being drawn. However, at first glance, the order of magnitude of the $\mathrm{F}$ content is comparable in both cases ( 10-50 at\%).

The $\mathrm{F}$ incorporation in the ZTO matrix is very efficient: $\mathrm{F}$ atomic concentration varies from $10 \%$ to more than $50 \%$ (the $[\mathrm{F}] /([\mathrm{Sn}]+[\mathrm{Zn}])$ ratio varies from 0.25 to more than 2.5 ) with $\mathrm{SF}_{6}$ flow increasing from $0.07 \%$ to $1.0 \%$. These values are larger but comparable to those generally used in $\mathrm{ZnO}: \mathrm{F}^{21}$ or $\mathrm{SnO}_{2}: \mathrm{F}^{22}$ doped layers. The $\mathrm{F}$ increase goes along with an $\mathrm{O}$ concentration decrease (the $([\mathrm{O}]+[\mathrm{F}]) /([\mathrm{Zn}]+[\mathrm{Sn}]$ ratio however slightly increase, see Table S1). No clear trend can be drawn concerning the impact of $\mathrm{SF}_{6}$ on the $[S n] /([S n]+[Z n])$ ratio.

Additionally, it can be noticed that the $\mathrm{F}$ content raises as well with the deposition pressure and with adding $\mathrm{O}_{2}$ in the carrier gas at constant $\mathrm{SF}_{6}$ flow. This counter-intuitive results is attributed to a better $\mathrm{SF}_{6}$ decomposition and $\mathrm{F}$ atoms liberation in the presence of $\mathrm{O}^{23}$. Additionally, no $\mathrm{S}$ has been detected in the layers (Table S1).

Transmission spectra of the ZTO:F layers ( $250 \mathrm{~nm}$ deposited on glass) are depicted in Figure 5 (b). At low $\mathrm{SF}_{6}$ flow $(<0.25 \%)$, transmission curves are almost unaffected by the $\mathrm{F}$ content, despite $[\mathrm{F}] /([\mathrm{Zn}]+[\mathrm{Sn}])$ ratio up to 1.5 can be measured in the layers. Only a small blue shift of the bandgap is visible and no free carrier absorption at long wavelengths is obtained, contrary to results in $\mathrm{ZnO}: \mathrm{F}^{21}$ and $\mathrm{SnO}_{2}: \mathrm{F}^{24}$ doped layers. Thus, the ability of $\mathrm{F}$ to act as a shallow dopant in ZTO layers is not demonstrated. At higher $\mathrm{SF}_{6}$ flow, a strong sub-bandgap absorption is observed. Although lower sheet resistance is observed with $\mathrm{Ar}: \mathrm{SF}_{6}$ reactive sputtering ( $\mathrm{R} \square$ increases with $\mathrm{SF}_{6}$ content in the range of $100-4000 \Omega . \square^{-1}$ ), no clear doping tendencies can be extracted from Hall measurements. Additionally, ZTO:F air-annealing at $200^{\circ} \mathrm{C}$ for $30 \mathrm{~min}$ induces a 4 to 6 orders of magnitude increase of the layer resistivity.
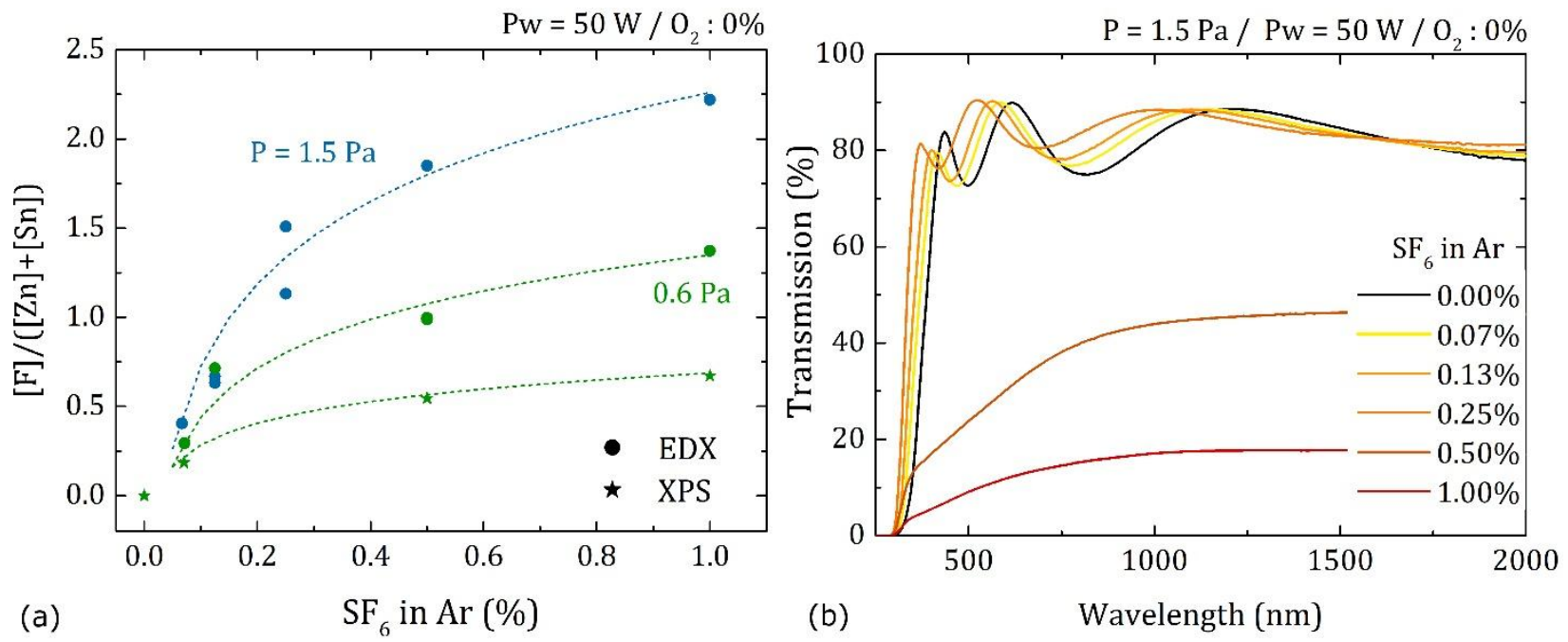

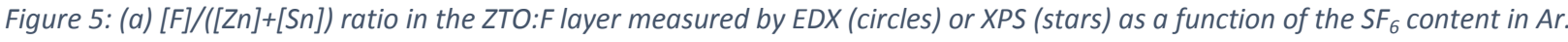
Depositions have been made at $1.5 \mathrm{~Pa}$ (blue) or $0.6 \mathrm{~Pa}$ (green). Dashed lines are guides for the eyes. (b) Transmssion curves of the ZTO:F layers deposited on glass with various $\mathrm{SF}_{6}$ content in $\mathrm{Ar}$.

XPS spectra of the ZTO:F layers deposited at various $\mathrm{SF}_{6}$ flows have been performed to shed light on the $F$ incorporation. Survey spectra are shown in Figure $S 1$ (a). Zn 2p3/2, Sn 3d5/2, $O$ 1s and $F$ 1s peaks are depicted in Figure 6. Both $\mathrm{Zn}$ and $\mathrm{Sn}$ contributions exhibit a similar behavior, which is a shift towards 
higher binding energies with increasing $\mathrm{SF}_{6}$ flow up to $0.5 \%$ and a stabilization at larger flow. The shift is attributed to $\mathrm{F}$ enrichment in the chemical environment of the $\mathrm{Zn}$ or $\mathrm{Sn}$, which is more electronegative than $\mathrm{O}^{20}$. The $\mathrm{F}$ peak shows only one contribution at $\sim 684 \mathrm{eV}$ for all samples reactively deposited with $\mathrm{SF}_{6}$, which can be attributed to $\mathrm{ZnF}_{2}{ }^{25}$ or $\mathrm{SnF}_{2}{ }^{26}$. Concerning the $\mathrm{O} 1 \mathrm{~s}$ peak, the picture is more complex: different contributions can be identified; fits of the $0 \%$ and $1 \% \mathrm{SF}_{6}$ samples spectra are shown for clarity. The low energy peak ( $530 \mathrm{eV}$ ) can be attributed both to $\mathrm{Zn}-\mathrm{O}^{27}$ and $\mathrm{Sn}-\mathrm{O}^{20}$ bonds in the matrix. For both $\mathrm{ZnO}$ and $\mathrm{SnO}_{2}$ materials, the intermediate energy contribution ( $531.8 \mathrm{eV}$ ) is related to oxide lattice with $\mathrm{O}$ vacancies ${ }^{20,27}$ and the high energy contribution ( $\sim 33.1 \mathrm{eV}$, not visible at $\left.0.0 \% \mathrm{SF}_{6}\right)$ is related to chemisorbed hydroxides ${ }^{20,27}$. The binding energy of the $\mathrm{Zn}-\mathrm{O}$ bonds for all contributions is systematically few tenth of eV more energetic than the $\mathrm{Sn}-\mathrm{O}$ bonds, leading to peaks broadening.

At low $\mathrm{F}$ contents, the width of the low energy peak decreases (particularly at low energy) while the Odeficient zone peak increases and the high energy peaks starts to appear. At higher $\mathrm{SF}_{6}$ flow $(0.5 \%)$, the low energy peak starts to decrease with a shift to higher energies with a continuous increase of the intermediate energy peak (which becomes predominant at $1.0 \% \mathrm{SF}_{6}$ ). The peak related to chemisorbed hydroxides remains at low level. This behavior, different to those observed both for $\mathrm{SnO}_{2}{ }^{20}$ and $\mathrm{ZnO}^{28}$ can be explained by the following mechanism: the $\mathrm{F}$ atoms preferably replace $\mathrm{O}$ in the stoichiometric zone of $\mathrm{SnO}_{2}$ which explains the reduction of the low energy peak width and the formation of $\mathrm{O}$ vacancies due to induced lattice distortion ${ }^{20}$. At higher $\mathrm{SF}_{6}$ contents, $\mathrm{O}$ in stoichiometric $\mathrm{ZnO}$ is replaced as well (low energy peak shrinkage). However, the magnitude of the O-Zn and/or O-Sn bonds signals from the O-deficient zone is unexpected and remains unexplained. To conclude, the $\mathrm{F}$ atom are replacing $\mathrm{O}$ from stoichiometric zones, first in $\mathrm{SnO}_{2}$ and then in $\mathrm{ZnO}$. It seems to foster as well the formation of $\mathrm{ZnO}$ and/or $\mathrm{SnO}_{2}$ deficient in $\mathrm{O}$.

Last, high resolution XPS spectra focused on the expected position of the S $2 p$ peaks (Figure S1 (b)) confirm that no $S$ is incorporated in the ZTO:F layers. 

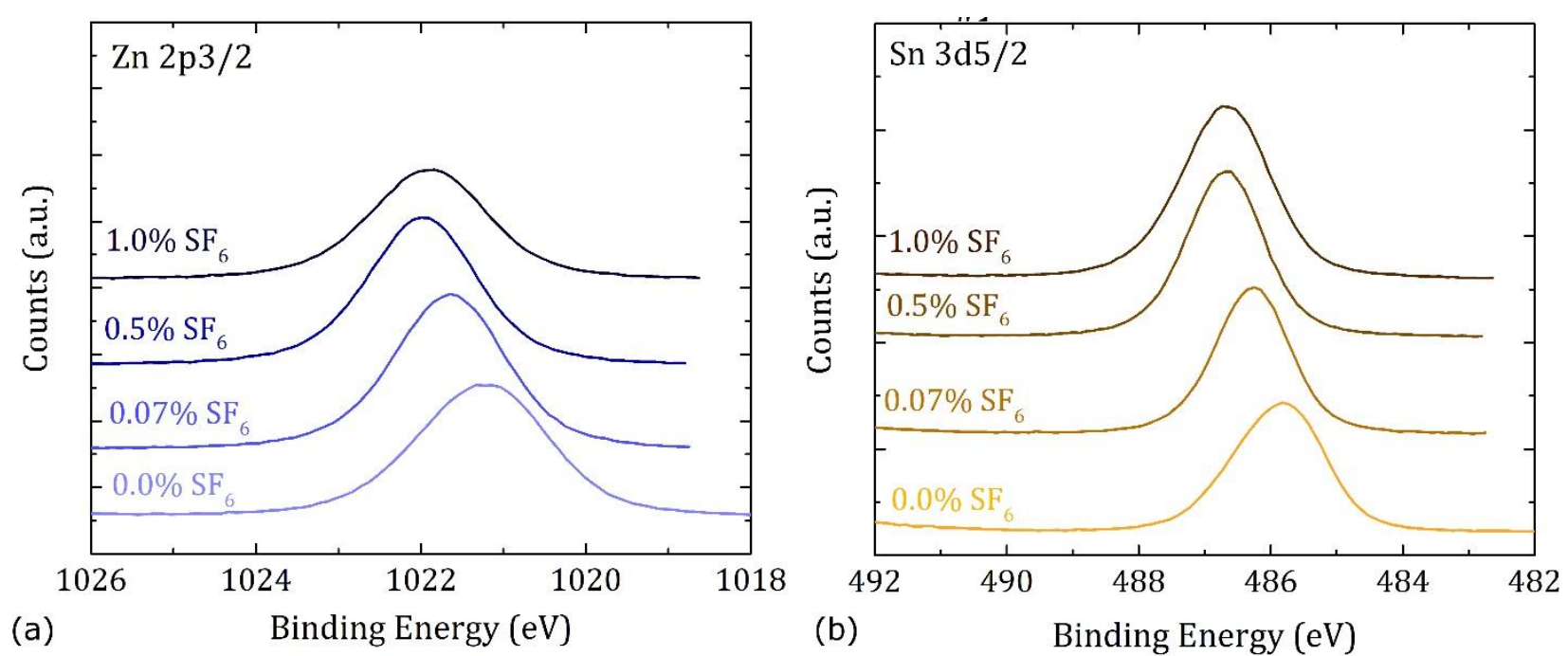

(a) Binding Energy $(\mathrm{eV})$

(b)

Binding Energy (eV)

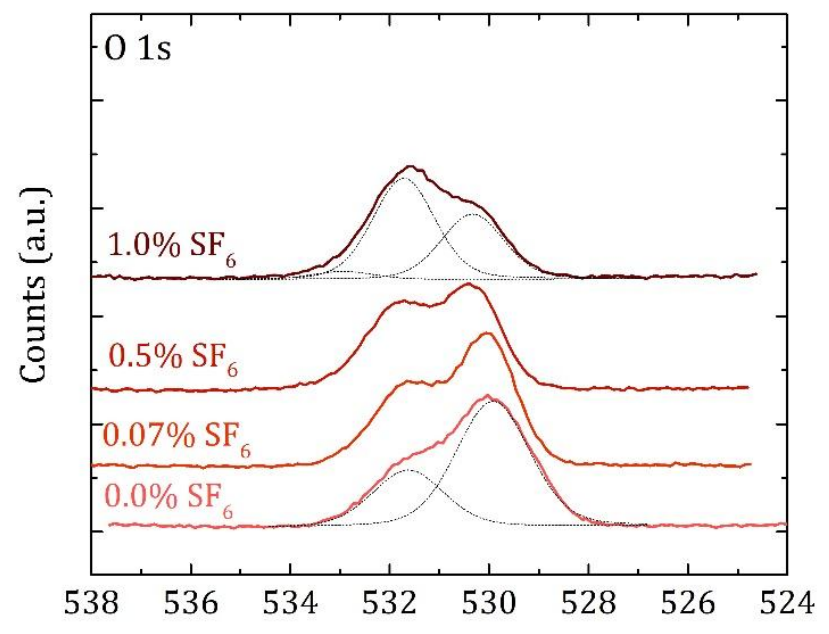

(c) Binding Energy (eV)

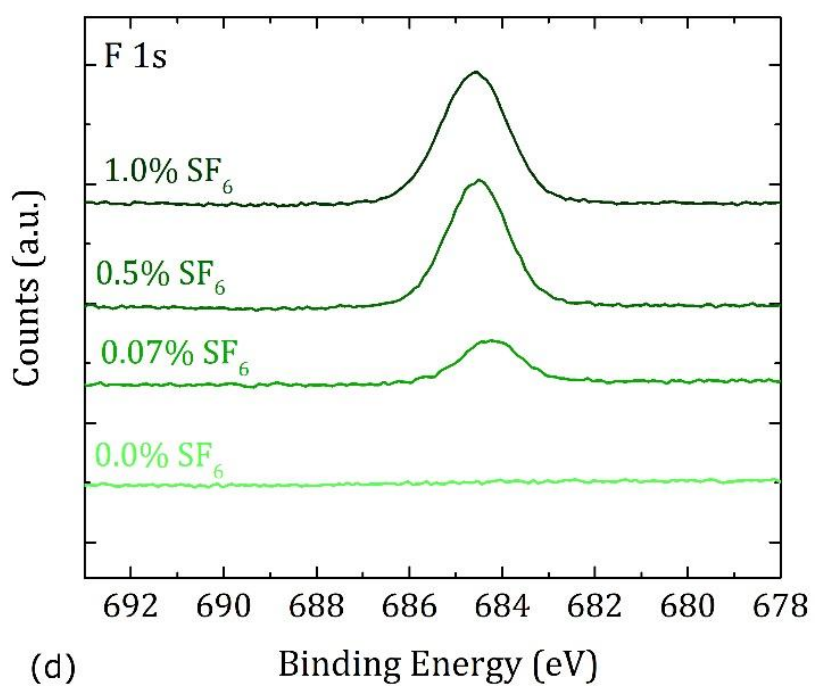

Figure 6: High resolution XPS spectra focused on the (a) $\mathrm{Zn2p}$, (b) Sn3d, (c) O1s and (d) F1s peaks as a function of the SF 6 content in the carrier gas. Fits of the curves for the $01 \mathrm{~s}$ peaks $\left(0.0 \% S F_{6}\right.$ and $\left.1.0 \% S F_{6}\right)$ are shown as well with thin dotted lines.

\subsection{Integration in devices}

\subsubsection{Sample preparation and optimization}

After the exploration of the ZTO deposition conditions and the characterization of the sputtered layers, optimization of the CZTS/ZTO/ZnO:Al has been conducted. The first measurements of the as-deposited solar cells with the alternative buffer layer gives very limited PCE (in the 1-2\% range), with an S-shape behavior in the fourth quadrant and very low current. After annealing the whole device at $200^{\circ} \mathrm{C}$ for 30 min in air, all PV properties (FF, $\mathrm{V}_{\mathrm{OC}}$ and $\mathrm{J}_{\mathrm{SC}}$ ) are significantly improved (Figure 7 (a)). Additional gain is obtained with a light soaking (LS) treatment, which consists in illuminating the whole device under simulated AM1.5 solar spectrum for a significant duration ( $>1$ hour) before measuring the cell. In the following, the post-deposition treatment $\left(200^{\circ} \mathrm{C}-30 \mathrm{~min}\right.$ annealing $\left.+\mathrm{LS}\right)$ has been applied to all devices before measurements. 

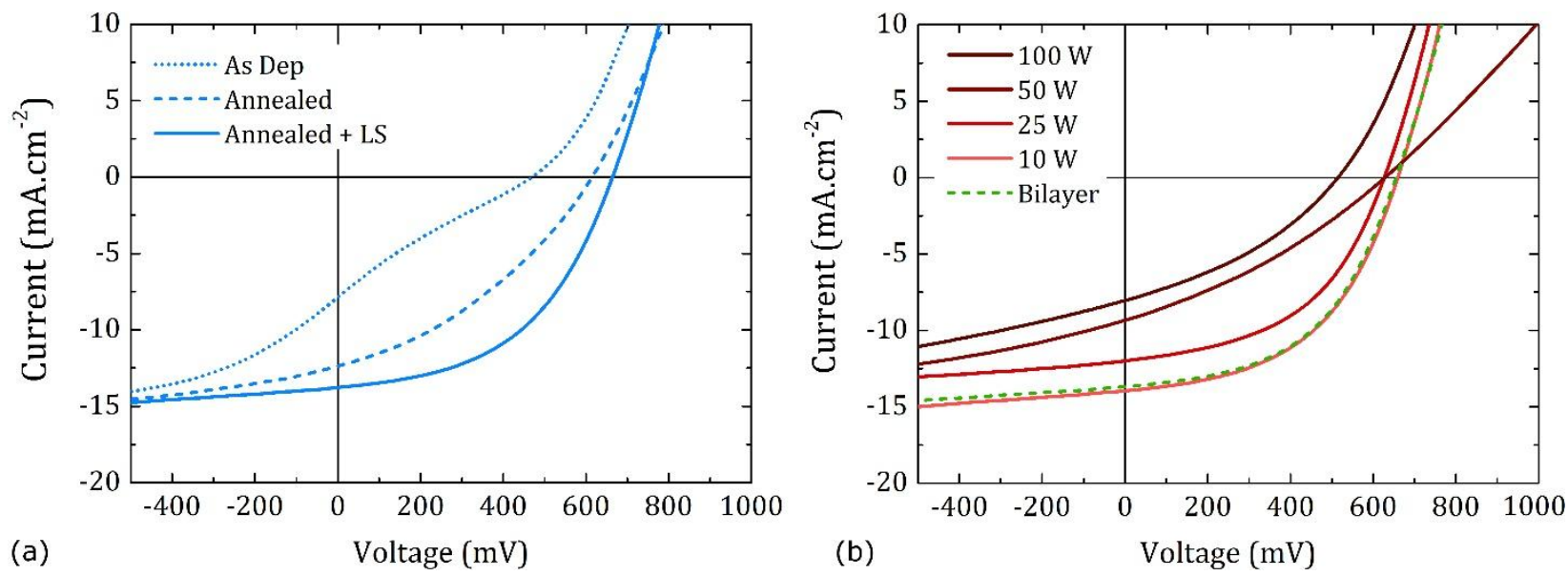

Figure 7: (a) J-V curves of a CZTS/ZTO/ZnO:Al solar cell as fonction of the post-deposition treatment: as deposited, after 30 min annealing at $200^{\circ} \mathrm{C}$ in air and after annealing and light soaking treatment. (b) J-V curves of a CZTS/ZTO/ZnO:Al solar cell as fonction of the ZTO deposition power. Bilayer is a $5 \mathrm{~nm} / 45 \mathrm{~nm}$ deposited at $10 \mathrm{~W} / 50 \mathrm{~W}$ respectively.

First, the impact of the ZTO sputtering power on the PV properties of the CZTS/ZTO/ZnO:Al devices has been tested. $50 \mathrm{~nm}$ buffer layers deposited at 10,25, 50 and $100 \mathrm{~W}$ have been used and the J-V curves of the solar cells are shown in Figure 7 (b). From these graphs, it is clear that deposition powers as low as possible must be used for the ZTO buffers. However, decreasing the power from $100 \mathrm{~W}$ to $10 \mathrm{~W}$ goes along with a deposition speed drop from $15 \mathrm{~nm} \cdot \mathrm{min}^{-1}$ to $0.25 \mathrm{~nm} \cdot \mathrm{min}^{-1}$. To suppress this $160 \mathrm{~min}$ sputtering step, a ZTO bilayer has been developed. The first $5 \mathrm{~nm}$ are deposited at $10 \mathrm{~W}$ followed by 45 $\mathrm{nm}$ deposited at $50 \mathrm{~W}$, reducing the deposition time to about $25 \mathrm{~min}$. As shown in Figure 7 (b), the PV properties of the solar cells with a $10 \mathrm{~W}$ ZTO layer and with a ZTO bilayer are exactly similar. A $6 \mathrm{~W} / 50 \mathrm{~W}$ bilayer has been tested as well but without improving the performances. It is hypothesized that the use of high power deposition damages the absorber surface and reduces the device performances. The thin $10 \mathrm{~W}$ layer would protect the CZTS surface at the beginning of the process. However, it cannot be totally excluded that the power effect is linked to a change in ZTO composition. At $10 \mathrm{~W}$, the $[\mathrm{Sn}] /([\mathrm{Sn}]+[\mathrm{Zn}])$ ratio is decreased to less than $19 \%$ (Figure 2), which might be more favorable for the CZTS/ZTO heterojunction. A $5 \mathrm{~nm}$ layer could be sufficient to optimize the heterojunction band offset.

The thickness of the buffer layer has then be optimized. As shown in Figure 8, the PCE of the CZTS/ZTO/ZnO:Al devices is relatively independent of the ZTO thickness (in a reasonable $15-50 \mathrm{~nm}$ range) and decreases at thicker values. This result is in contradiction with the optimization of the devices with ALD deposited ZTO, which are very sensitive to the buffer thickness ${ }^{9}$. It would allow to further decrease the ZTO deposition time to less than 15 min by using thinner buffers without reducing the performances.

Although the effect of ZTO reactive sputtering with $\mathrm{O}_{2}$ does not change significantly the optical properties of the layer (Figure 4), it has a significant impact on the CZTS/ZTO/ZnO:Al device properties as shown in Figure 8. At small $\mathrm{O}_{2}$ content, PCE increases with $\mathrm{O}_{2}$ but an optimum is reached in the $0.2 \%-0.8$ $\%$ range. This gain in efficiency is mainly related to $\mathrm{V}_{\mathrm{OC}}$ improvement $\left(622 \mathrm{mV}\right.$ for the $0 \% \mathrm{O}_{2}$ and $721 \mathrm{mV}$ at $0.2 \% \mathrm{O}_{2}$ and a current variation of less than $1 \mathrm{~mA} \cdot \mathrm{cm}^{-2}$ ). The bilayer strategy with $\mathrm{O}_{2}$ only used in the second ZTO deposition stage has been used, but without modifying the device properties. 


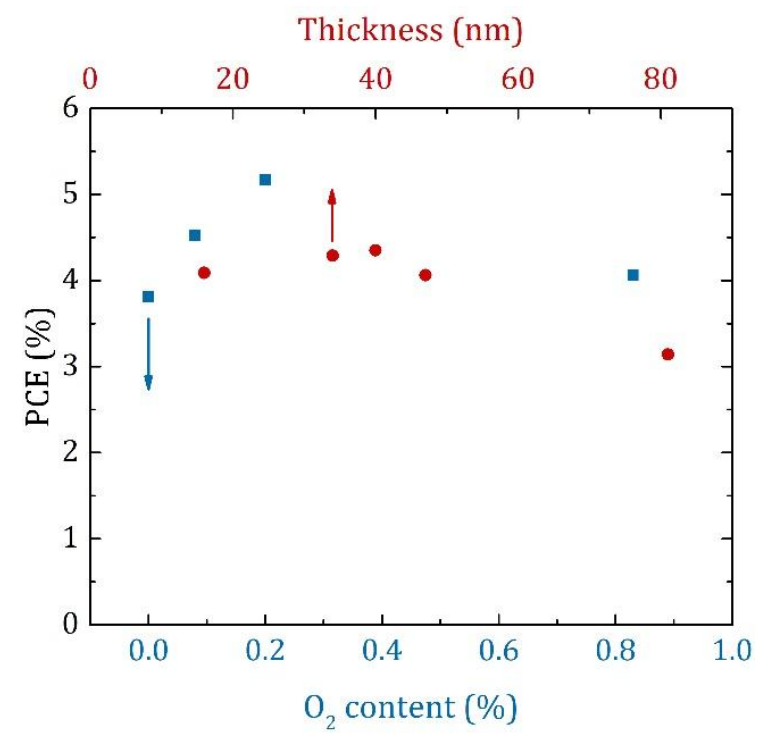

Figure 8: PCE of the CZT/ZTO/ZnO:Al devices as a function of the ZTO thickness (red, top scale) and as a function of the $\mathrm{O}_{2}$ ratio in the carrier gas (blue, bottom scale)

A further attempt to improve the CZTS/ZTO/ZnO:Al devices performances consist in using a doped ZTO:F buffer layer. Due to the very efficient $F$ incorporation in ZTO:F with $\mathrm{SF}_{6}$ content in Ar carrier gas (Figure 5), a low $0.03 \% \mathrm{SF}_{6}$ has been used for the ZTO:F buffer deposition. A first attempt to deposit the whole ZTO bilayer in the reactive $\mathrm{Ar}_{\mathrm{SF}} \mathrm{SF}_{6}$ gas conducts to a severe rollover effect in the fourth quadrant despite the standard post-deposition treatment (Figure $9(\mathrm{a})$ ). Hypothesizing a detrimental effect of $\mathrm{SF}_{6}$ on the CZTS absorber surface, the bilayer strategy has been further extended to ZTO:F deposition. A first $5 \mathrm{~nm}$ sublayer has been sputtered at $10 \mathrm{~W}$ and without $\mathrm{SF}_{6}$, followed by a $40 \mathrm{~nm}$ sublayer sputtered at $50 \mathrm{~W}$ with $0.03 \% \mathrm{SF}_{6}$ in carrier gas. $\mathrm{No}_{2}$ is used in this case. As a result, the rollover effect disappears (Figure 9 (a)) and the solar cell with the ZTO:F buffer layer (PCE $=4.7 \%$ ) slightly surpasses the cell with the reference ZTO buffer layer (deposited with $0 \% \mathrm{O}_{2}, \mathrm{PCE}=3.81 \%$ ) and as well the cell with the reference CdS buffer layer (PCE $=4.6 \%)$. The best performing cell sputtered in Ar:O2 $(0.2 \%)$ exhibits mainly larger $\mathrm{J}_{\mathrm{SC}}\left(+1.28 \mathrm{~mA} \cdot \mathrm{cm}^{-2}\right)$ and $\mathrm{V}_{\mathrm{OC}}(+17 \mathrm{mV})$. 

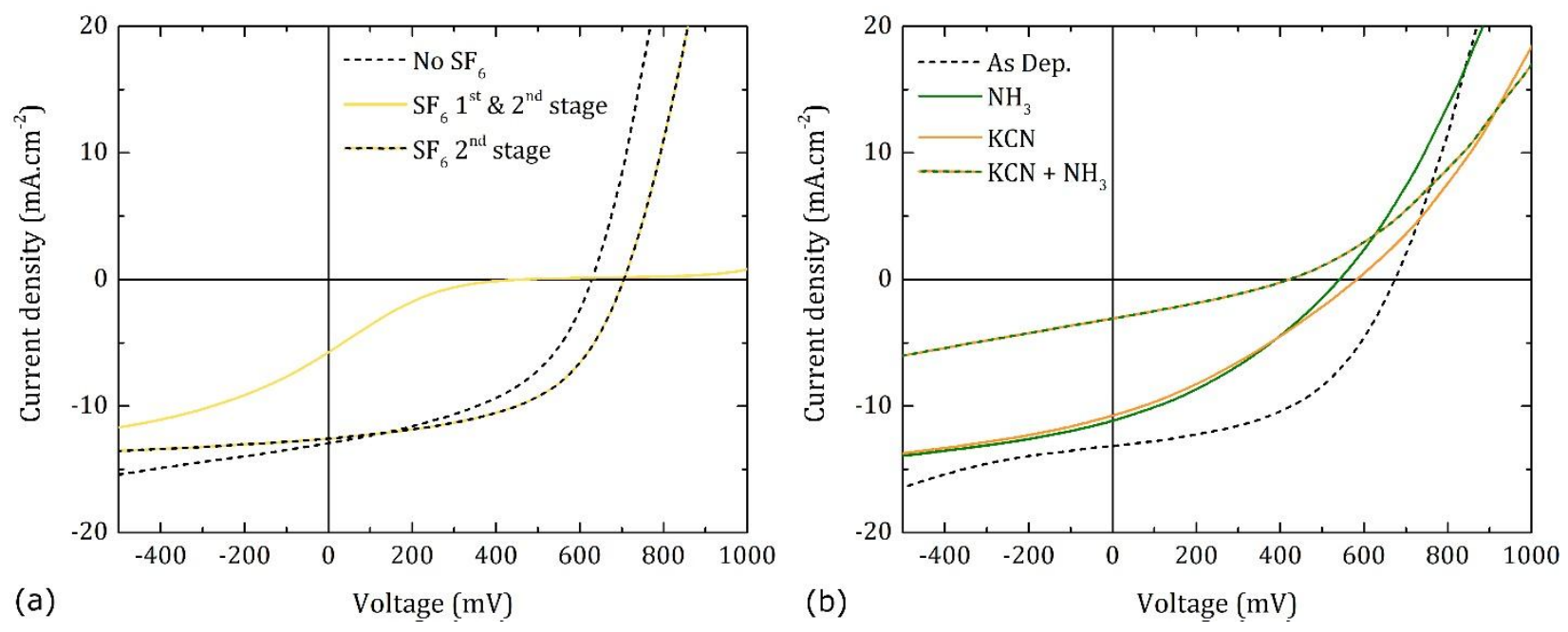

Figure 9: (a) J-V curves of the CZTS/ZTO:F/ZnO:Al solar cells. (b) J-V curves of the CZTS/ZTO/ZnO:Al solar cells as a function of the CZTS surface preparation

It is often said that the use of CBD for buffer deposition gives the best results since the absorber surface is subject to chemical cleaning during the bath ${ }^{11}$. It is worth noting that for all devices presented previously, ZTO buffer have been deposited on bare absorbers without any chemical cleaning stage. To ensure that the lack of chemical cleaning does not imply a performance drop in the solar cells, an additional cleaning step has been tested between absorber synthesis and buffer sputtering. First the absorbers have been etched in an ammonia solution ( $\mathrm{NH}_{3} 4.5 \%$ for 2 minutes at room temperature), which reproduces the basic solution of the CdS bath. A KCN solution (KCN 2\%w/V for 2 minutes at room temperature ${ }^{29}$ ) has been tested as well and the combination of $\mathrm{KCN}$ and $\mathrm{NH} 3$ etchings too. The results are depicted in Figure 9 (b). It shows that all chemical etching procedures degrade the efficiency of the devices, particularly because of reducing their FF. Thus, the use of a ZTO sputtered buffer layer is perfectly compatible with full PVD processes since no chemical surface preparation is necessary before its deposition.

\subsubsection{Record cell with CZTS vs CZTSe}

In the following are presented the PV properties of the best CZTS/ZTO/ZnO:Al device along with those of a reference CZTS/CdS/i-ZnO/ZnO:Al device made on the same batch of absorbers. The optimized ZTO layer has been transferred as well on a CZTSe absorber but no specific optimization of the sputtered buffer layer has been made on Se-containing material. The synthesis process of CZTS and CZTSe are very comparable. In both cases (for CZTS and CZTSe absorbers), the ZTO buffer is a $50 \mathrm{~nm}$ bilayer ( $5 \mathrm{~nm} / 45$ $\mathrm{nm}$ ) deposited at $10 \mathrm{~W} / 50 \mathrm{~W}$ with a $1.5 \mathrm{~Pa} \mathrm{Ar}: \mathrm{O}_{2} \quad 0.2 \%$ pressure and without any surface treatment nor cleaning before the sputtering process.

J-V curves under AM1.5 simulated spectrum and in the dark are depicted in Figure 10 (a). First, the CZTSbased solar cell with a ZTO buffer exhibits a higher PCE $(+0.6 \%$, Table 1$)$ than the reference device with a $\mathrm{CdS}$ buffer layer. This better performance is mainly due to a higher $\mathrm{V}_{\mathrm{OC}}(>100 \mathrm{mV}$, Table 1). Similar improvements have been obtained with a ALD deposited ZTO buffer layer and attributed to reduced interface recombination ${ }^{8}$. The EQE spectra depicted in Figure 10 (b) show a similar maximum EQE ( 70\%) for both devices. The main difference between CZTS/CdS and CZTS/ZTO devices can be found at short wavelengths. A significant increase is obtained in the second case, which is of course partly due to 
the reduced absorption in the buffer layer when replacing the low bandgap $\mathrm{CdS}{ }^{30}$. However, this contribution is not sufficient and as shown in another study, the reduction of interface recombination can notably improve the short wavelength EQE ${ }^{31}$. This latter result confirms the analysis conducted in ref. ${ }^{8}$. It is noticeable as well that the long wavelength EQE cut-off is shifted to shorter wavelengths for the cells with ZTO buffer layer. CZTS bandgaps extracted from the maximum of the EQE first derivative are $1.49 \mathrm{eV}$ (with $\mathrm{CdS}$ ) and $1.56 \mathrm{eV}$ (with ZTO) respectively. This latter effect is linked to the postdeposition treatment (annealing in air at $200^{\circ} \mathrm{C}$ for $30 \mathrm{~min}$ ) and can partially be explained by Cu- $\mathrm{Zn}$ ordering ${ }^{32}$. This $70 \mathrm{mV}$ larger bandgap explains part of the $\mathrm{V}_{\mathrm{OC}}$ improvement (along with interface recombination reduction).

Concerning CZTSe-based solar cells, the picture is totally different. While devices with the reference CdS buffer layer exhibit reasonable PV properties (PCE $=8.6 \%$ without anti-reflecting coating), the device with ZTO is drastically limited by a low FF (a reverse diode is visible) and an insufficient $\mathrm{J}_{\text {sC }}$ (Figure 10 (a)) leading to a PCE $=3.1 \%$ (Table 1 ). Although the CdS replacement by ZTO allows to improve the EQE at short wavelengths (Figure 10 (b)), it limits the EQE maximum to $60 \%$ which explains the low current. Again, this low EQE can be explained by a photocurrent barrier. It is worth noting as well that the short wavelength gain is less pronounced than for CZTS-based devices. As the CdS absorption is similar in both cases, this discrepancy arises from a larger reduction of the interface recombination with ZTO in the first case.
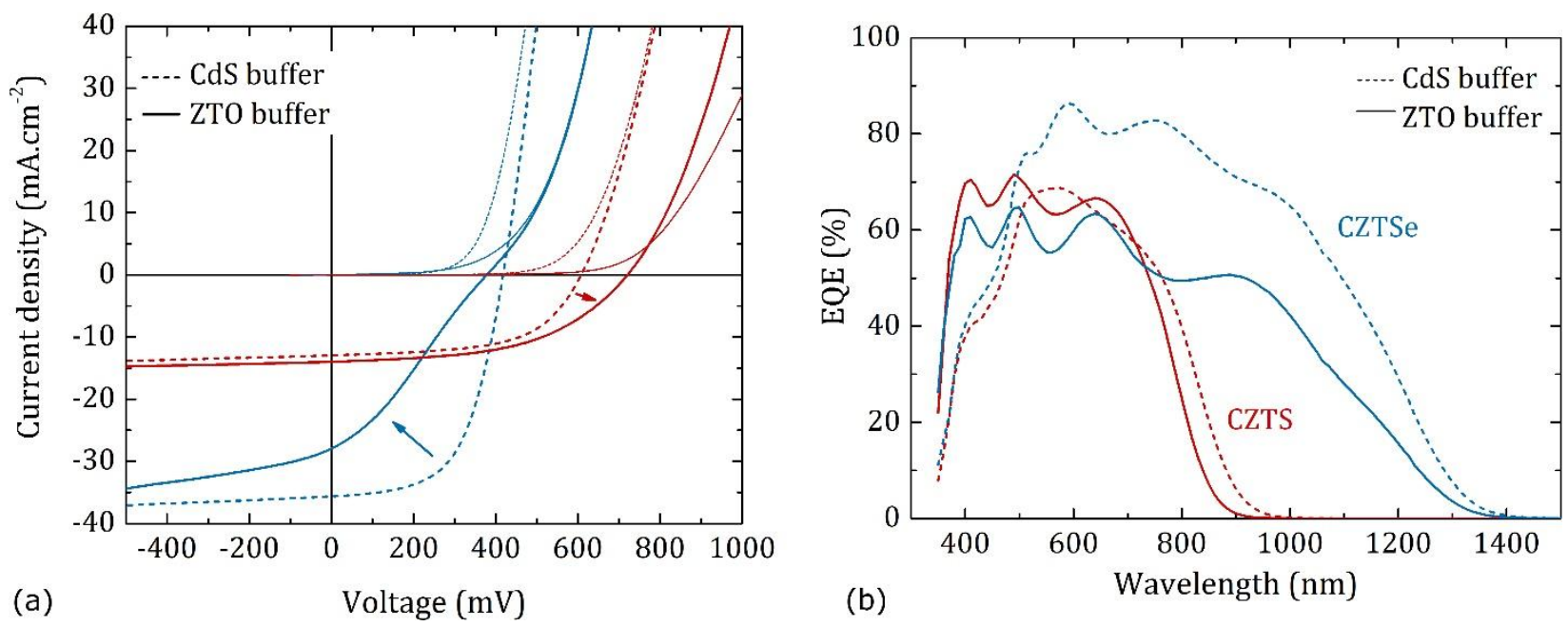

Figure 10: (a) J-V curves of the best CZTS- (red) and CZTSe- (blue) based solar cells with a ZTO (continuous line) or a reference CdS (dashed line) buffer layer measured under AM1.5 simulated solar spectrum. Dark J-V curves of the same devices are also depicted with thinner lines (same symbols). (b) EQE spectra of the same solar cells.

Table 1: PV properties of the best solar cells for CZTS and CZTSe absorbers with CdS and ZTO buffer layers respectively extracted from JV-curves and EQE depicted in Figure 10.

\begin{tabular}{|c|c|c|c|c|c|c|c|c|c|}
\hline \multirow[b]{2}{*}{ Abs. } & \multirow[b]{2}{*}{ Buffer } & \multicolumn{4}{|c|}{ Light } & \multicolumn{4}{|c|}{ Dark } \\
\hline & & $\begin{array}{l}\text { PCE } \\
\text { (\%) }\end{array}$ & $\begin{array}{l}\text { FF } \\
(\%)\end{array}$ & $\begin{array}{l}\mathrm{V}_{\mathrm{OC}} \\
(\mathrm{mV})\end{array}$ & $\begin{array}{c}J_{\mathrm{Sc}} \\
\left(\mathrm{mA} \cdot \mathrm{cm}^{-2}\right)\end{array}$ & $\begin{array}{c}\mathrm{J}_{0} \\
\left(\mathrm{~mA} \cdot \mathrm{cm}^{-2}\right)\end{array}$ & $n$ & $\begin{array}{c}R_{\text {Sh }} \\
\left(\Omega . \mathrm{cm}^{2}\right)\end{array}$ & $\begin{array}{c}R_{\mathrm{S}} \\
\left(\Omega . \mathrm{cm}^{2}\right)\end{array}$ \\
\hline \multirow{2}{*}{ CZTS } & ZTO & 5.2 & 51.4 & 721 & 14.0 & $8.23 \times 10^{-5}$ & 2.7 & 7400 & 6.74 \\
\hline & $C d S$ & 4.6 & 58.3 & 615 & 12.9 & $1.16 \times 10^{-4}$ & 2.16 & 19600 & 2.26 \\
\hline \multirow{2}{*}{ CZTSe } & ZTO & 3.1 & 29.3 & 380 & 27.8 & $2.67 \times 10^{-2}$ & 3.12 & 770 & 1.34 \\
\hline & $C d S$ & 8.6 & 57.9 & 415 & 35.7 & $1.71 \times 10^{-3}$ & 1.71 & 2600 & 1.02 \\
\hline
\end{tabular}


This comparison emphasizes the fact that the ZTO buffer layer seems to be better-suited for S-rich absorbers than for Se-rich absorbers. In most of the studies, ZTO buffer layers are used with pure sulfide CZTS absorbers. In reference ${ }^{17}$, a CZTSSe/ZTO-based solar cell with $8.60 \%$ efficiency is fabricated, which is slightly higher than the performance of the reference CZTSSe/CdS-based device (8.14\%). From this study and references ${ }^{9,16-17}$, it can be noticed that the relative efficiency gain of a CZTSSe/ZTO-based device (compared to the reference CZTSSe/CdS-based device) increases with the $[\mathrm{S}] /([\mathrm{S}]+[\mathrm{Se}]$ ) ratio. For pure CZTSe absorber, PCE is decreased by $63 \%$. For $[\mathrm{S}] /([\mathrm{S}]+[\mathrm{Se}]) \sim 28 \%$, a $5 \%$ relative improvement is obtained $^{17}$ while for pure sulfide compounds, relative improvements from $13 \%$ (this study) to $19 \%$ are achieved $^{9,16}$. It is attributed to a more favorable band alignment of the CZTS/ZTO junction compared to the CZTSe/ZTO junction. The position of the CZTSe conduction band is indeed at least $0.3-0.5 \mathrm{eV}$ higher than the one of CZTS ${ }^{7}$. For the CZTS/ZTO junction, a small positive band-offset can be expected while for CZTSe/ZTO junction, a detrimental negative band offset is expected ${ }^{17}$. Due to these band alignments, the CZTSe/ZTO interface is likely to be much more recombinant than the CZTS/ZTO interface.

\section{Conclusion}

In this study, the use of sputtered ZTO layers as promising buffer layers for CZTS-based solar cells is demonstrated. First, the structural and optical properties of ZTO layers deposited from a single ZnSnO target are detailed. An amorphous ZTO layer is obtained regardless of the deposition temperature, while a significant change in layer composition (from $Z_{0.75} T_{0.25} O$ to $Z_{0.82} T_{0.18} O$ ) is possible by decreasing the sputtering power from $200 \mathrm{~W}$ to $10 \mathrm{~W}$. While the use of $\mathrm{Ar}: \mathrm{O}_{2}$ reactive sputtering only slightly improves the short wavelength transmission of the layers, the possibility of integrating substantial amounts of $F$ in the layer using $\mathrm{Ar}: \mathrm{SF}_{6}$ reactive sputtering has been demonstrated. Additional studies are requested to demonstrate the ability of doping ZTO using this method. ZTO layers have been used as buffer layers in CZTS/ZTO/ZnO:Al solar cells. It is shown that using a two stage sputtering process with a first ultrathin low power sublayer allows to reach significant performances after an annealing and light soaking treatment. Optimization of the process with reactive sputtering (with $\mathrm{Ar}: \mathrm{SF}_{6}$ and more markedly with $\mathrm{ArO}_{2}$ ) allows to reach performances larger than the solar cell with a reference CdS buffer layer. A 5.2\% efficient device has been fabricated without any chemical cleaning of the absorber surface. These results are very promising for the integration of sputtered ZTO buffer layers for the CZTS solar cells made by full PVD processes.

\section{Acknowledgements}

This research was supported by the H2020 Program under the project STARCELL (H2020-NMBP-03-2016720907).

\section{References}

1. Nakamura, M.; Yamaguchi, K.; Kimoto, Y.; Yasaki, Y.; Kato, T.; Sugimoto, H., Cd-Free $\mathrm{Cu}(\mathrm{In}, \mathrm{Ga})(\mathrm{Se}, \mathrm{S})_{2}$ Thin-Film Solar Cell With Record Efficiency of 23.35\%. IEEE Journal of Photovoltaics 2019, 9 (6), 1863-1867.

2. Katagiri, H.; Saitoh, K.; Washio, T.; Shinohara, H.; Kurumadani, T.; Miyajima, S., Development of thin film solar cell based on $\mathrm{Cu}_{2} \mathrm{ZnSnS}_{4}$ thin films. Solar Energy Materials and Solar Cells 2001, 65 (1-4), 141-148. 
3. Wang, W.; Winkler, M. T.; Gunawan, O.; Gokmen, T.; Todorov, T. K.; Zhu, Y.; Mitzi, D. B., Device characteristics of CZTSSe thin-film solar cells with 12.6\% efficiency. Advanced Energy Materials 2014, 4 (7), 1301465.

4. Green, M. A.; Hishikawa, Y.; Dunlop, E. D.; Levi, D. H.; Hohl-Ebinger, J.; Yoshita, M.; Ho-Baillie, A. W. Y., Solar cell efficiency tables (Version 53). Prog Photovoltaics 2019, 27 (1), 3-12.

5. Bermudez, V.; Perez-Rodriguez, A., Understanding the cell-to-module efficiency gap in $\mathrm{Cu}(\mathrm{In}, \mathrm{Ga})(\mathrm{S}, \mathrm{Se})_{2}$ photovoltaics scale-up. Nature Energy 2018, 3 (6), 466.

6. Valentini, M.; Malerba, C.; Serenelli, L.; Izzi, M.; Salza, E.; Tucci, M.; Mittiga, A., Fabrication of monolithic CZTS/Si tandem cells by development of the intermediate connection. Solar Energy 2019, 190, 414-419.

7. $\quad$ Platzer-Björkman, C.; Barreau, N.; Bär, M.; Choubrac, L.; Grenet, L.; Heo, J.; Kubart, T.; Mittiga, A.; Sanchez, Y.; Scragg, J., Back and front contacts in kesterite solar cells: state-of-the-art and open questions. Journal of Physics: Energy 2019, 1 (4), 044005.

8. $\quad$ Platzer-Björkman, C.; Frisk, C.; Larsen, J.; Ericson, T.; Li, S.-Y.; Scragg, J.; Keller, J.; Larsson, F.; Törndahl, T., Reduced interface recombination in $\mathrm{Cu}_{2} \mathrm{ZnSnS}_{4}$ solar cells with atomic layer deposition $\mathrm{Zn}_{1-\mathrm{x}} \mathrm{Sn}_{\mathrm{x}} \mathrm{O}_{\mathrm{y}}$ buffer layers. Applied Physics Letters 2015, 107 (24), 243904.

9. $\quad$ Cui, X.; Sun, K.; Huang, J.; Lee, C.-Y.; Yan, C.; Sun, H.; Zhang, Y.; Liu, F.; Hossain, M. A.; Zakaria, Y., Enhanced Heterojunction Interface Quality To Achieve 9.3\% Efficient Cd-Free $\mathrm{Cu}_{2} \mathrm{ZnSnS}_{4}$ Solar Cells Using Atomic Layer Deposition ZnSnO Buffer Layer. Chemistry of Materials 2018, 30 (21), 7860-7871.

10. Cui, X.; Sun, K.; Huang, J.; Yun, J. S.; Lee, C.-Y.; Yan, C.; Sun, H.; Zhang, Y.; Xue, C.; Eder, K., CdFree $\mathrm{Cu}_{2} \mathrm{ZnSnS}_{4}$ solar cell with an efficiency greater than $10 \%$ enabled by $\mathrm{Al}_{2} \mathrm{O}_{3}$ passivation layers. Energy \& Environmental Science 2019, 12 (9), 2751-2764.

11. Naghavi, N.; Abou-Ras, D.; Allsop, N.; Barreau, N.; Bücheler, S.; Ennaoui, A.; Fischer, C. H.; Guillen, C.; Hariskos, D.; Herrero, J., Buffer layers and transparent conducting oxides for chalcopyrite $\mathrm{Cu}(\mathrm{In}, \mathrm{Ga})(\mathrm{S}, \mathrm{Se})_{2}$ based thin film photovoltaics: present status and current developments. Progress in Photovoltaics: Research and Applications 2010, 18 (6), 411-433.

12. Bras, P.; Sterner, J.; Platzer-Björkman, C., Influence of hydrogen sulfide annealing on copperzinc-tin-sulfide solar cells sputtered from a quaternary compound target. Thin Solid Films 2015, 582, 233-238.

13. Grenet, L.; Suzon, M. A. A.; Emieux, F.; Roux, F., Comparing strategies for improving efficiencies in vacuum processed $\mathrm{Cu}_{2} \mathrm{ZnSnSe}{ }_{4}$ solar cells. Journal of Renewable and Sustainable Energy 2018, 10 (4), 043503.

14. Hayashi, Y.; Kondo, K.; Murai, K.; Moriga, T.; Nakabayashi, I.; Fukumoto, H.; Tominaga, K., ZnO$\mathrm{SnO}_{2}$ transparent conductive films deposited by opposed target sputtering system of $\mathrm{ZnO}$ and $\mathrm{SnO}_{2}$ targets. Vacuum 2004, 74 (3-4), 607-611.

15. Kapilashrami, M.; Kronawitter, C. X.; Törndahl, T.; Lindahl, J.; Hultqvist, A.; Wang, W.-C.; Chang, C.-L.; Mao, S. S.; Guo, J., Soft X-ray characterization of $\mathrm{Zn}_{1-x} \mathrm{Sn}_{\mathrm{x}} \mathrm{O}_{\mathrm{y}}$ electronic structure for thin film photovoltaics. Physical Chemistry Chemical Physics 2012, 14 (29), 10154-10159.

16. Larsen, J. K.; Larsson, F.; Törndahl, T.; Saini, N.; Riekehr, L.; Ren, Y.; Biswal, A.; Hauschild, D.; Weinhardt, L.; Heske, C., Cadmium free $\mathrm{Cu}_{2} \mathrm{ZnSnS}_{4}$ solar cells with 9.7\% efficiency. Advanced Energy Materials 2019, 1900439.

17. Li, X.; Su, Z.; Venkataraj, S.; Batabyal, S. K.; Wong, L. H., 8.6\% Efficiency CZTSSe solar cell with atomic layer deposited Zn-Sn-O buffer layer. Solar Energy Materials and Solar Cells 2016, 157, 101-107. 18. Rozgonyi, G.; Polito, W., Preparation of $\mathrm{ZnO}$ thin films by sputtering of the compound in oxygen and argon. Applied Physics Letters 1966, 8 (9), 220-221.

19. Yoon, H.; Lee, K.; Lee, T.; Cheong, B.; Choi, D.-K.; Kim, D.; Kim, W., Properties of fluorine doped $\mathrm{ZnO}$ thin films deposited by magnetron sputtering. Solar Energy Materials and Solar Cells 2008, 92 (11), 1366-1372. 
20. Wang, X.; Wang, X.; Di, Q.; Zhao, H.; Liang, B.; Yang, J., Mutual effects of fluorine dopant and oxygen vacancies on structural and luminescence characteristics of $\mathrm{F}$ doped $\mathrm{SnO}_{2}$ nanoparticles. Materials 2017, 10 (12), 1398.

21. Hu, J.; Gordon, R. G., Textured fluorine-doped $\mathrm{ZnO}$ films by atmospheric pressure chemical vapor deposition and their use in amorphous silicon solar cells. Solar cells 1991, 30 (1-4), 437-450.

22. Agashe, C.; Major, S., Effect of heavy doping in $\mathrm{SnO}_{2}: \mathrm{F}$ films. Journal of materials science 1996, 31 (11), 2965-2969.

23. Plank, N.; Blauw, M.; Van der Drift, E.; Cheung, R., The etching of silicon carbide in inductively coupled $\mathrm{SF}_{6} / \mathrm{O}_{2}$ plasma. Journal of Physics D: Applied Physics 2003, 36 (5), 482.

24. Elangovan, E.; Ramamurthi, K., A study on low cost-high conducting fluorine and antimonydoped tin oxide thin films. Applied surface science 2005, 249 (1-4), 183-196.

25. Polydorou, E.; Zeniou, A.; Tsikritzis, D.; Soultati, A.; Sakellis, I.; Gardelis, S.; Papadopoulos, T. A.; Briscoe, J.; Palilis, L. C.; Kennou, S., Surface passivation effect by fluorine plasma treatment on ZnO for efficiency and lifetime improvement of inverted polymer solar cells. Journal of Materials Chemistry $A$ 2016, 4 (30), 11844-11858.

26. York-Winegar, J.; Harper, T.; Brennan, C.; Oelgoetz, J.; Kovalskiy, A., Structure of $\mathrm{SnF}_{2}-\mathrm{SnO}_{2} \mathrm{P}_{2} \mathrm{O}_{5}$ glasses. Physics Procedia 2013, 44, 159-165.

27. Hsieh, P.-T.; Chen, Y.-C.; Kao, K.-S.; Wang, C.-M., Luminescence mechanism of ZnO thin film investigated by XPS measurement. Applied Physics A 2008, 90 (2), 317-321.

28. Choi, Y.-J.; Kang, K.-M.; Park, H.-H., Anion-controlled passivation effect of the atomic layer deposited $\mathrm{ZnO}$ films by $\mathrm{F}$ substitution to O-related defects on the electronic band structure for transparent contact layer of solar cell applications. Solar Energy Materials and Solar Cells 2015, 132, 403409.

29. Fairbrother, A.; García-Hemme, E.; Izquierdo-Roca, V.; Fontané, X.; Pulgarín-Agudelo, F. A.; VigilGalán, O.; Pérez-Rodríguez, A.; Saucedo, E., Development of a selective chemical etch to improve the conversion efficiency of $\mathrm{Zn}$-rich $\mathrm{Cu}_{2} \mathrm{ZnSnS}_{4}$ solar cells. Journal of the American Chemical Society 2012, 134 (19), 8018-8021.

30. Grenet, L.; Grondin, P.; Coumert, K.; Karst, N.; Emieux, F.; Roux, F.; Fillon, R.; Altamura, G.; Fournier, H.; Faucherand, P., Experimental evidence of light soaking effect in $\mathrm{Cd}$-free $\mathrm{Cu}_{2} \mathrm{ZnSn}(\mathrm{S}, \mathrm{Se})_{4^{-}}$ based solar cells. Thin Solid Films 2014, 564, 375-378.

31. Suzon, M. A. A.; Grenet, L.; Emieux, F.; De Vito, E.; Roux, F.; Mariette, H., Effect of Sb and Na Incorporation in $\mathrm{Cu}_{2} \mathrm{ZnSnS}_{4}$ Solar Cells. physica status solidi (a) 2019, 216 (11), 1900070.

32. Larsen, J. K.; Ren, Y.; Ross, N.; Särhammar, E.; Li, S.-Y.; Platzer-Björkman, C., Surface modification through air annealing $\mathrm{Cu}_{2} \mathrm{ZnSn}(\mathrm{S}, \mathrm{Se})_{4}$ absorbers. Thin Solid Films 2017, 633, 118-121. 